\title{
New Resources for Childbirth Educators and Parents
}

\author{
Coordinated by Teri Shilling, MS, CD(DONA), IBCLC, LCCE, FACCE
}

\begin{abstract}
In this column, reviewers offer perspectives and comments on a variety of new media resources for childbirth educators and for expectant and new parents. The books and DVDs reviewed in this issue's column address the following topics: new directions for childbirth education classes; pregnancy tips for expectant mothers; empowering women to give birth naturally; midwifery care; breastfeeding; labyrinths and "laborinths" (an alternative approach to preparing for birth); preterm labor; understanding newborns' language cues; and exercise programs during pregnancy and the postnatal period, as well as exercises that strengthen the pelvic floor and help new mothers deal with incontinence.
\end{abstract}

The Journal of Perinatal Education, 18(3), 63-72, doi: 10.1624/105812409X461252

Keywords: breastfeeding, childbirth education, midwifery care, natural birth, newborns, parenting, pelvic floor exercises, postnatal exercises, pregnancy, pregnancy exercises, preterm labor

\section{Birth and Parenting Skills: New Directions in} Antenatal Education

Editors: Mary L. Nolan and Julie Foster, with foreword by Nola Ishmael

Publisher: Churchill Livingstone (2005, 2nd edition)

Softcover: 176 pages

Cost: $\$ 49.95$

Where to order: Available at most major bookstores and online booksellers (including www. elsevierhealth.com)

It's no secret that educators are having a difficult time encouraging expectant parents to take childbirth classes. Many of us struggle to figure out strategies that help us reach more families. Birth and Parenting Skills: New Directions in Antenatal Education examines factors that dictate the content of prenatal classes and describes recent pilot programs designed to present information in a way that is more accessible to class participants. Although Birth and Parenting Skills contains some interesting ideas, its content is both too general and too specific in addressing ways childbirth education can be updated to become more relevant to today's families.

Birth and Parenting Skills alternates between the general philosophy of childbirth education and actual programs that have been attempted. One of the more interesting ideas presented in the book is the description of a "Birth Ideas Workshop," in which the typical hospital tour is used as a starting point to engage parents in an in-depth educational experience. The description of the workshop is very detailed, even indicating what questions to ask and how to facilitate the parent-led discussion. The lesson plan allows for thorough discussions on pain, the value and purpose of pain in childbirth, and the role 
of support people in birth, as well as an attempt to identify and address the parents' fears. The breadth of suggested information presented in the workshop's estimated 2 hours is staggering, and I cannot see how couples could really be given a chance to have a free discussion in such a short period of time. However, if the time constraint is removed, I would like to attempt such a format in one of my own classes.

Most of the innovative programs described in Birth and Parenting Skills were created within the framework of the British health-care system. Consequently, some translation is required to understand where the programs could fit into the framework of other health-care systems.

Birth and Parenting Skills may be especially helpful for childbirth educators or directors of childbirth education programs to use for ideas in revamping their curriculum. Some of the ideas presented in the book (e.g., how to present the bottleversus-breastfeeding topic in classes so that parents feel more open to participate in the discussion) could easily be implemented by any educator in her classes. However, most of the programs, while innovative, might be out of reach for almost every independent childbirth educator. For this reason, I advise the purchase of this book only if an educator or program director intends to supplement other, more thorough resources.

Reviewer:

Veronica Jacobsen, CD(DONA), CLC, LCCE Woodbury, $\mathrm{MN}$

The Complete Illustrated Pregnancy Companion: A Week-by-Week Guide to Everything You Need to Do for a Healthy Pregnancy

Author: Robin Elise Weiss, LCCE, CD(DONA), with Marcello Pietrantoni, MD, FACOG

Publisher: Fair Winds Press (2009)

Softcover: 320 pages, with 300 photos and illustrations

Cost: $\$ 21.99$

Where to order: Available at most major bookstores and online booksellers

While skimming through Robin Elise Weiss' latest book, The Complete Illustrated Pregnancy Companion, I knew I would love it when my eyes landed on the following subheading: "Avoid Baby-Related Reality Television." How many times have we had to undo that damage in our childbirth classes?

Weiss' new book is filled with sage little nuggets of advice, such as how to make a rice sock, things to consider when choosing a name ("Do the initials spell anything rude?"), and to consider your bellybutton ring. Reading this book is like having a conversation about pregnancy with a wise friend.

Written for pregnant women, each chapter in The Complete Illustrated Pregnancy Companion corresponds to each of the 40 weeks of pregnancy, with subsequent chapters devoted to 41 weeks and beyond, labor and birth, and the postpartum period. For each week, Weiss packages a wealth of information into easily digestible chunks, beginning with a succinct weekly checklist of things to think about, plan, and do. For example, the checklist for Week 21 includes the following suggestions for expectant mothers: buy a birth ball, start planning for your maternity leave, try a new pregnancy exercise, and check on your life insurance. Weiss also describes what is likely to be going on with the mom's body, what is likely to be going on with the baby's growth, and a list of "what to watch for" each week-which, refreshingly, sidesteps the fear that can accompany a similar list of warning signs found in other mainstream pregnancy books.

But the best stuff, in my opinion, is the upbeat extras sprinkled throughout every chapter in The Complete Illustrated Pregnancy Companion. The affirmations and "Hot Mama" tips are fabulous, and they reinforce the everyday wonder of pregnancy and birth. Weiss manages to plant dozens of seeds of positivity, gently and repeatedly reminding the reader that she is beautiful, pregnancy is miraculous, and childbirth is normal.

The book itself is delightfully designed, filled with rich photographs and serene colors. This is an accessible book that can easily appeal to mainstream readers. It is a fast read, and even the casual skimmer just flipping through can pick up valuable morsels of knowledge. The Complete Illustrated Pregnancy Companion is a welcome addition to my lending library and ranks at the top of my list of books that I recommend to pregnant women.

Reviewer:

Amy Goforth, LCCE

Borden, IN

Gentle Birth, Gentle Mothering: A Doctor's Guide to Natural Childbirth and Gentle Early Parenting Choices

Author: Sarah J. Buckley, MD, with foreword by Ina May Gaskin, CPM 
Publisher: Celestial Arts (2009; updated from an earlier version published in 2005)

Softcover: 348 pages

Cost: $\$ 16.95$

Where to order: Available at most major bookstores and online booksellers

Gentle Birth, Gentle Mothering, by Dr. Sarah Buckley, covers everything expectant parents need to consider during pregnancy. Dr. Buckley reviews standard prenatal testing and intersperses her research with her own personal experiences. The book contains 68 pages of resources and footnotes. This updated version of Dr. Buckley's original 2005 publication includes endnotes for all chapters at the end of the book rather than at the end of each chapter, which made it a little more difficult for me to find the particular reference I wanted to review.

Chapter 4, titled "Your Body, Your Baby, Your Choice: A Guide to Making Wise Decisions," has enough valuable information to justify the price of the book. It covers informed consent, how to choose a provider, and differences between screening tests and diagnostic tests. The chapter also includes an explanation of gestation diabetes and the diagnostics and treatment for this condition. Dr. Buckley rightly states, "Please remember that informed choice, including informed refusal, is your right in every situation. ..." Her book is an excellent resource for expectant parents to take with them as a reference during prenatal visits with their healthcare providers and when questioning them about any testing or procedure they might recommend.

Gentle Birth, Gentle Mothering is written for new parents. Dr. Buckley thoroughly and precisely covers ultrasound testing because she feels that parents are generally not given sufficient, accurate information to make an informed choice about this technology. The ultrasound information is especially valuable not only for the new parent-to-be, but also for any childbirth educator who wants more in-depth information regarding the safety and efficacy of the ultrasound equipment and testing procedures.

I wonder, though, if it is worth investing in this updated version of Gentle Birth, Gentle Mothering. OnherWebsite(www.sarahjbuckley.com), Dr. Buckley delineates the updated and new material, compared to the original 2005 version of Gentle Birth, Gentle Mothering. She lists six completely new sections, in addition to 15 updated and expanded sections.

Part 2 of Gentle Birth, Gentle Mothering covers breastfeeding, attachment parenting, extended nursing, and safe co-sleeping. Dr. Buckley discusses the baby's brain wiring and how it responds to early interactions and experiences. Although Dr. Buckley discusses some topics that are not necessarily mainstream practices (e.g., lotus birth or unassisted birth), she does not advocate these practices for everyone; instead, she advises women to pay attention to their intuition.

I disagree with Dr. Buckley regarding the theory of evolution; however, I cannot argue with her heartfelt sentiment for families or her vast amount of clinical experience and valuable body of collected research. Gentle Birth, Gentle Mothering is at the top of my favorites list, and I highly recommend it to others.

$$
\begin{array}{r}
\text { Reviewer: } \\
\text { Denise Easthon, CD(DONA), ELCS, LCCE } \\
\text { Beavercreek, OH }
\end{array}
$$

\section{Empowered to Birth Naturally: One Woman's Journey to Homebirth}

Author: Patrice A. London

Publisher: Booklocker.com, Inc. (2008)

Softcover: 116 pages, including 40 pages of photos

Cost: $\$ 7.00$ (eBook download); \$12.95 (paperback)

Where to order: Online at www.booklocker.com

As conveyed in the book's title, Empowered to Birth Naturally presents the story of how the author, Patrice London, became empowered to give birth naturally and, specifically, describes her personal journey to homebirth. Like most birth professionals, I enjoy reading and hearing others' birth stories, especially when they entail the inspiring transformation of their experiences and the effects on their lives. London describes her journey, which includes her first (hospital) birth, second (birth center) birth, a miscarriage, her subsequent homebirth, and her hopeful plans for another homebirth in the future. She merges reflections from all of her birth attendees, including her children and her husband, with a review of her own final thoughts and with photos from her homebirth.

I think Empowered to Birth Naturally would be a great book for a pregnant woman who is having trouble finding her faith in birth and in herself. Also, a woman who has previously had a less-thanpositive birth experience may find the book helpful in finding her own path to a more fulfilling future birth experience. It may also provide good information for helping a woman to convince her partner and other support people of her desired birth center 
To view each of the Lamaze Healthy Birth Practices (formerly known as the "Six Care Practices That Support Normal Birth") and to read about the evidence-based research that supports these practices, $\log$ on to the Lamaze Web site (www.lamaze.org).

To view the Lamaze approaches to pregnancy, birth, and parenting, log on to the Lamaze Web site (www.lamaze.org), click on "About Lamaze," and click on "Mission and Vision." or homebirth. Additionally, Empowered to Birth Naturally could be a useful tool for childbirth educators and other birth professionals to recommend or loan to women in the situations described above.

Although the homebirth photos included in Empowered to Birth Naturally are a bit fuzzy, they do help to reinforce London's birth story. The photos show great moments during London's labor and birth process together with her children, her husband, her midwives, her doula, her mother, and her friends - a laboring mother at home, surrounded by love, family, friends, and support. Along with London's written descriptions of her homebirth, the photos also depict London's independence as a laboring woman to choose her preferred birthing activities (including some fun dancing with her children and support people), environment, support persons, positions, and vocalizations, which can be so contrary to hospital births.

London does an insightful job at promoting the six Lamaze Healthy Birth Practices. Though she admits to membrane sweeping and castor oil early in her homebirth labor, London's progress remains on its own initiation and accord. There were no routine interventions, and pushing began spontaneously and concluded in a birth pool with no separation of mom and baby, including delayed cord clamping.

Empowered to Birth Naturally would be a great reading requirement for childbirth students or $\mathrm{OB} /$ midwife patients. London's accounts would surely lead to interesting follow-up conversations and discussions and, possibly, serve as a tool for mind-set transformation.

London's writing style is very personable, as if she is just sitting with you, telling you her story. Empowered to Birth Naturally is quick and easy to read. London admits her bias toward natural birth and midwives, but she also expresses gratitude toward the obstetric medical field in necessary situations.

Having recently attended my first homebirth as a doula, I easily related to London's journey described in Empowered to Birth Naturally. I also have a few doula clients in mind who would likely benefit from loaning them my copy of the book. For a fairly small purchasing price, Empowered to Birth Naturally may spark life-changing transformations for expectant mothers, doulas, and childbirth educators.

Reviewer:

Rebecca J. Metheny, CD(DONA), CLS, LCCE Morgantown, WV
Labor of Love: A Midwife's Memoir

Author: Cara Muhlhahn, CNM, with foreword by Abby Epstein and Ricki Lake

Publisher: Kaplan Publishing (2009)

Hardcover: 272 pages

Cost: $\$ 25.95$

Where to order: Available at most major bookstores and online booksellers

Labor of Love is a memoir by Cara Muhlhahn, the certified nurse-midwife made famous by Abby Epstein and Ricki Lake in their 2007 documentary film The Business of Being Born. A quick and entertaining read, Labor of Love is an excellent introduction to the world of modern childbirth and, especially, to homebirth midwifery.

At its core, Labor of Love is the life story of a strong and passionate woman who answers her calling to be a midwife and, then, a mother, learning both joyful and painful lessons at every juncture. Muhlhahn describes her life from the beginning, literally! She begins by reflecting on her own time in utero and speculates about why she was born a double-footling breech.

Muhlhahn then chronicles her growing up years, her discovery of direct-entry midwifery "Out West" in the United States, her professional detour into jazz singing before pursuing nursing studies, her work as a hospital midwife, and, finally, her transition to homebirth practice in, of all places, New York City. Woven into her narrative are important insights about modern childbirth and the needs of birthing women today. Muhlhahn's descriptions of the births she attends and of the level of care, attention, and expertise she offers her clients-all birthing under very different circumstances-are remarkable reminders of what is lacking in institutional-style maternity care. Anyone reading her story cannot help but wonder why every woman does not have a midwife like Muhlhahn looking out for her.

Labor of Love reflects the Lamaze Approach to Birth and demonstrates the benefits of the six Lamaze Healthy Birth Practices. Muhlhahn's book would be especially useful for women who are curious about midwifery or are exploring the possibility of homebirth for the first time.

Because Labor of Love is a personal memoir, some biases and strong viewpoints of the author naturally come across, and topics are addressed in the book that some would consider "hot-button" issues. Lamaze educators should preview the book for their own particular clients before adding it 
to their group library. That being said, Labor of Love is a delightful book that most educators, parents, and anyone interested in birth, motherhood, or the lives of strong women can read with enjoyment and profit.

Reviewer:

Pamela H. Pilch, JD, LCCE

Richmond, VA

The Wonderful Place

Author: Chrissy Butler

Publisher: Chrissy Butler (2008)

Softcover: 26 pages, with color illustrations

Cost: $\$ 22$

Where to order: Online at www.chrissybutler.com

Chrissy Butler's The Wonderful Place is a beautifully written and illustrated short story regarding breastfeeding and extended feeding with children. It is written almost like a poem, with short phrases. However, Butler's message is clear, especially considering the infant's point of view toward breastfeeding: "Mother's milk makes me happy and it is a wonderful place to be." Butler also points out a few of the fun side effects for breastfeeding infants, such as pinching mommy's skin, calming down from a hurt boo-boo, and wriggling away as well as snuggling close.

The main audience for The Wonderful Place is breastfeeding parents, but I believe the book could also be used in a childbirth class for expectant parents or in a nursing support group where extended feeders may gather. Butler's book does not serve as a reference for breastfeeding questions; rather, it offers beautiful examples of how breastfeeding and extended feeding can be amazing for a child and parent.

Butler's original illustrations are particularly impressive in The Wonderful Place. Each page in the book includes a loose, yet clearly drawn picture of what feedings look like and can accomplish. Each illustration not only completes the words on the page but also adds an additional level of interest in breastfeeding and could be used in classrooms and offices as an artwork representation of extended feeding at its best. The Wonderful Place embodies the Lamaze Approach to Parenting by showing how breastfeeding creates a bond that is beyond the infant stage, showing pictures of not only young children but older ones, too.

In The Wonderful Place, Butler clearly has a set vision: She believes in extended breastfeeding and is not ashamed or embarrassed of feeding in any circumstance. She does not speak as an authority on the matter; instead, she speaks as a parent who loves to breastfeed her children. You can tell by the words and circumstances in the book that Butler has breastfed her children through many years and loves each time, knowing that every feeding has a purpose. Although The Wonderful Place is a short book, I love the simple message of how special and rewarding breastfeeding can be, and I especially enjoy seeing a parent illustrate and write on this subject so passionately.

Reviewer: Amy Podgurski-Gough, LCCE Wheeling, WV

\section{When the Labyrinth Becomes a Laborinth}

Author: Pam England

Publisher: Birthing From Within (2008)

Softcover: 60 pages, plus a packet of six labyrinth "seeds"

Cost: $\$ 12$

Where to order: Online at www.birthingfromwithin. com

Pam England's book, When the Labyrinth Becomes a Laborinth, is designed to supplement England's Birthing from Within book or class but could certainly be used by those pursuing other preparation for birth. The enclosed six labyrinth "seeds" are 41/2by-41/2-inch cards with a specific labyrinth shape on the front of the card, and on the back it shows how to reproduce that particular shape.

In the book's introduction, England does a nice job of detailing the history of labyrinths. She notes that labyrinths are ancient; one in Sardinia is estimated to be 3,500 years old. Many labyrinths are found in Scandinavia where they were believed to capture violent winds that could harm ships. Fishermen walked the labyrinths seven times before heading out to sea, believing that bad spirits or trolls attached to them would be trapped in the labyrinth's center. England also tells how, 500 years ago, midwife-healers in Cromwell used labyrinths with pregnant women to answer questions or to heal by holding the question in their mind while humming and tracing a labyrinth etched in slate. When a midwife-healer died, her slate was either passed down to an apprentice or buried with her.

The "Anatomy and Glossary" section of When the Labyrinth Becomes a Laborinth details the parts of a seven-circuit labyrinth. England shows how it 
differs from a maze and notes that the classic sevencircuit labyrinth is the most widely used around the world. She describes the significance of the number seven and includes the Hindu yantra, the square and round Hopi labyrinths, and the Man in the Maze as examples of the seven-circuit labyrinth.

In the chapter "Labyrinths of the World," England discusses the animal- and geometric-shaped labyrinths in Peru, which are so big they can only be appreciated from the air. She also identifies the differences between the square and round Hopi labyrinths. The square one is a labyrinth within a labyrinth and is referred to as the "Mother-child" because the outer labyrinth holds the inner one as a mother would hold a child. England details the symbolism of the various areas within the square labyrinth and points out that it has two entrances. In contrast, the round Hopi labyrinth has different meanings and is included in Hopi ceremonies.

In the next section of her book, England declares that labor is a labyrinth and notes that the turns in the labyrinth can be disorienting and parallel "unwished-for surprises that are a part of every labor." She uses the three phases of the Jungian Hero's Journey to describe the process: pregnancy represents the Preparation phase, labor represents the Ordeal phase, and postpartum represents the Return phase. England offers a nice discussion of what she calls the "Gate of Great Doubt," which is defined as the time in labor when most women experience doubt. England points out that moving through this gate may lead to the Gates of Trust and Faith. The birth takes place in the center of the "laborinth," producing both a baby and a mother. Stepping out on the return path to the entrance is the beginning of the postpartum period.

A yantra is another form of a labyrinth that has been used in India for 2,000 years to focus attention, eliminate mind chatter, and deepen meditation. This requires intense concentration and is thought to ease pain. Another approach in northwest India suggests that when women go into labor, they drink a saffron labyrinth. To do this, they rub saffron with water from the Ganges River and use it to draw a classical labyrinth on a bronze plate. The plate is rinsed with water from the river, and the laboring woman drinks the water to cause the birth to occur and to ease the pain.

England's book includes a chapter describing what a Birthing from Within laborinth looks like and featuring former students' drawings and comments. One student indicated he drew his laborinth on a rock because he wanted to be his partner's rock during labor. Another stated that there were footprints on the bottom of her drawing, representing the footprints of her mother, her grandmother, and her ancestors who had made the birth journey before her.

England provides directions for drawing a sevencircuit labyrinth, along with an explanation of right- and left-hand labyrinths, which refers to the direction one faces at the first turn in the labyrinth. Next, she instructs students to draw their footprints about 2 inches in front of the entrance of the labyrinth to represent their knowing and freedom. She also indicates that the footprints are there to remind them that they cannot "think" their way through labor but must act, move, and keep moving. Finally, students are asked to draw a threshold wide enough to cover the entrance and high enough for them to have to pause before entering the labyrinth. Thresholds, states England, are universal, architectural symbols of transition and transcendence. In birth, they separate the worlds of maidens and mothers.

In the middle of England's discussion about how to make a labyrinth is a section on the medical model's symbols. She identifies such items as a cervical dilation chart and a labor progress graph. This section seems to be misplaced, and in the "Table of Contents" it is listed earlier than it actually appears in the book.

England provides directions for making a clay laborinth and a sandbox laborinth, as well as how to walk a labyrinth. She has specific etiquette rules for walking a labyrinth, including walking in silence, turning off cell phones, refraining from picture taking or posing, and, when walking with a group, not making eye contact or talking when passing. England indicates that the center of the labyrinth is not a public altar and that items should not be left there. I would suggest that if no one else is walking a labyrinth and you feel like singing, skipping, or running on the pathway, do so. It is a very different experience than walking for meditation and can be equally revealing.

The next chapter in England's book addresses left-brain/right-brain issues. It examines the properties of Alpha, Beta, Theta, and Delta brain waves in a discussion of balancing the brain and changing brain wave patterns.

When the Labyrinth Becomes a Laborinth includes a section on meditations and rituals that can be practiced on the labyrinth. England suggests using 
the laborinth as soon as it is made to prepare for prenatal exams or to process what happened at the visit, to practice breath awareness while tracing or gazing at the laborinth, and to contemplate one's deepest question or to help make a decision. England also discusses ways to adapt the practice from northwest India of "drawing and drinking your labyrinth" in labor by substituting ingredients common to the American culture. She further describes some walking meditations and a spiral of light ceremony.

When the Labyrinth Becomes a Laborinth is both enlightening and creative. I recommend it to anyone who is looking for another avenue to access inner wisdom, especially during labor.

Reviewer:

Joyce Thomas DiFranco, RN, BSN, LCCE, FACCE, Labyrinth Facilitator Rancho Palos Verdes, CA

\section{FitBALL ${ }^{\circledR}$ USA's Great Expectations Pregnancy Program}

Producer: Ball Dynamics, with Lisa Westlake as instructor

Format: DVD (45 minutes)

Cost: Varies from $\$ 15.95-\$ 27.99$

Where to order: Google search provides several online venues

"Safe intensity" is the name of the game in Great Expectations Pregnancy Program, a new exercise DVD with instructor Lisa Westlake, a mother of two, a physiotherapist, and an Australian fitness leader. It is doubtful that this 45 -minute program will leave you hot or "puffed," which Westlake cautions against in the opening introductions. Newly pregnant women and women who are previously used to high-intensity or interval training workouts may be surprised at how gently this workout begins, especially the warm-up and cardio sections. But don't despair! After the stability ball comes into play, the exercise program gets a lot more challenging and fun.

Westlake uses the inherent instability of the ball to help exercisers challenge their abdominal and pelvic floor muscles. The descriptions of how to brace the abdominal muscles and pull up the pelvic floor leave no room for misunderstanding of how to get the most out of the strengthening and toning exercises. The most interesting and challenging sections of the DVD involve exercises on the ball, where one leg is off the ground, requiring mental concen- tration, abdominal bracing, and connection with your pelvic floor. Great fun! Westlake smartly includes terrific conditioning exercises for the upper body and, specifically, the upper back, an area that many women need to strengthen to comfortably nurse and hold their newborns for long periods of time.

If you're already in great shape, you may need to augment the Great Expectations Pregnancy Program DVD with your regular cardio workout. However, any expectant woman will appreciate this DVD for the specific conditioning and strengthening exercises chosen just for pregnant bodies.

Reviewer:

Kim James, ICCE, CD(PALS), LCCE Seattle, WA

\section{Lullaby Exercises}

Producer: chicks-n-chickens (2009)

Director: Darcy Novo Albrecht

Format: DVD (35 minutes); includes audio CD of the original soundtrack by Lisa Phenix

Cost: $\$ 29.95$

Where to order: Online at www.chicks-n-chickens. com

The Lullaby Exercises DVD features seven women with their babies in slings, exercising and then swaying with their babies to try to put them to sleep. The first five songs are devoted to exercise. The exercise portion lasts about 20 minutes and has a warm-up, then shows squats, legs/arms, cardio, and tummy exercises. The last third of the video has three songs, which are devoted to lulling the baby to sleep. This lullaby segment shows moms swaying and stretching while holding their baby in a sling. Lullaby Exercises is geared toward new moms trying to get back in shape while involving their baby, and also showing moms how to get their baby to sleep by using a sling.

Although I commend the producer for involving baby in mom's exercise, I found Lullaby Exercises to be somewhat amateurish. Also, the soundtrack music is something I would have expected to hear on a children's CD.

I liked that the moms had their babies in slings during exercise and lullaby time; however, due to the movement and being close to mom, a number of the babies in the video fell asleep during exercise time. It made me slightly uncomfortable to see the babies jostled around so much while they were sleeping. Also, the moms were focused on exercising 
and not interacting with their babies, but at least the babies were being held close.

The lullaby section might be good for modeling how to help a baby go to sleep by holding baby close and swaying and rocking. But beyond watching it once or twice, I would think a mother would want to focus on her baby while holding baby close rather than watching other moms and babies on a video.

Lullaby Exercises only shows mothers interacting with their babies. There are no fathers shown holding their babies in a sling. Furthermore, 6 of the 7 mothers were Caucasian, so the DVD does not depict much ethnic diversity.

Although exercising with a baby in a sling is a novel idea, overall, I do not feel Lullaby Exercises would be an asset for a childbirth educator to own or use in her classes.

Reviewer:

Anna Marie Nelson, BS, LMT, CD(DONA), LCCE

Palmer, TX

\section{Preterm Labor: Reduce Your Risks \& Learn the Signs}

Producer: InJoy Birth and Parenting Videos (2008)

Format: DVD and VHS (main program length, 14 minutes; bonus, 3:53 minutes)

Cost: $\$ 149.95$

Where to order: Online at Injoy Videos (www. injoyvideos.com) or call 800-326-2082

Preterm labor can happen to any pregnant woman. The key to a better birth outcome is knowledge of the signs and reduction of risk. Preterm Labor: Reduce Your Risks \& Learn the Signs is a good resource to have as a childbirth educator, health-care provider, or anyone who provides services to pregnant women. This video, narrated by an obstetrician, is intended to provide the expectant mother with the tools needed to reduce her risk of premature labor and to equip her to recognize the signs should they appear.

Preterm Labor is organized in three concise chapters: "What is Preterm Labor?"; "Who's at Risk?"; and "What are the Signs?". This layout makes this DVD a useful tool for childbirth educators to use in class and as resource material. Each chapter ranges from about 3-6 minutes in length, so the DVD could be easily used to introduce the topic or to use as a review. The DVD's simplicity of presentation works well if it were to be sent home with expectant parents. The video also includes a bonus section that presents a personal interview with a young Caucasian couple that experienced a preterm labor.

Preterm Labor does a great job comparing the characteristics of a preterm infant to a full-term infant, both physically and developmentally. It also reassures parents who have preterm infants that these babies usually catch up with their full-term peers in about $1-2$ years.

The video has a diverse cultural representationCaucasian, Asian, Latino/Hispanic-but it lacks much African-American representation. Although all pregnant women are at risk, researchers have shown that African-American women are twice as likely to experience preterm births (see www. marchofdimes.org). Although the information presented in Preterm Labor is universal, reception may be skewed in African-American populations. The video may give a false sense of an "other" race issue. In order to have greater impact, balanced racial and cultural representation of AfricanAmericans is needed.

Throughout the video, Preterm Labor supports the Lamaze Healthy Birth Practice concerning keeping baby and mother together, which is challenging in preterm situations. The video encourages close interaction between parents and child and encourages breastfeeding as best practice, even in the intensive care setting.

Reviewer:

Tonya Daniel, BA, LCCE Creedmoor, NC

\section{Dunstan Baby Language: Learn the Universal Language of Newborn Babies \\ Producer/Director: Dunstan Baby (2006)}

Cast: Priscilla Dunstan

Format: Set of two DVDs (total run time: $60 \mathrm{mi}-$ nutes); includes a 24-page booklet and a reference wall chart

Cost: $\$ 39.99$

Where to order: Available at most major bookstores and online booksellers, including Dunstan Baby (www.dunstanbaby.com) and Lamaze International Bookstore and Media Center (www.lamaze.org)

Unlike many other parenting resources that explain how to provide basic baby care but leave the clarification of when to trial and error, the Dunstan Baby Language program focuses on recognizing when to address each of baby's needs by learning baby's language. Targeted for parents of 1- to 3-monthold infants, the video features Priscilla Dunstan, 
an Australian mother, who claims her system will reduce parents' frustration and stress while enhancing bonding, building self-esteem, and boosting confidence.

Dunstan does not profess to be an expert. Instead, she is a mother who put her unique gift, a "photographic memory for sound," to use in helping her to more effectively respond to the cries of her colicky son. According to Dunstan, through careful listening and observation, she was able to discern a pattern in her son's cries, a rudimentary language consisting of five universal baby "words" that are the core of this system.

Both DVDs in Dunstan Baby Language follow a practical format. Each baby word is pronounced with a description of how the sound is made, what it signifies, and finally, to aid in identification, a 1-minute clip of various babies saying the word. In the second part, Dunstan uses a doll to demonstrate different ways to respond to each word.

The first DVD covers the words for hunger, tired, and need to burp, followed by several testimonies from satisfied mothers. The second DVD covers the words for gas and uncomfortable. It concludes with Dunstan addressing a group of mothers and their babies, classifying their babies' cries and offering solutions. In addition to the two DVDs and a reference wall chart, the Dunstan Baby Language program includes a 24-page booklet in which the system is summarized, research is reviewed, frequently asked questions are answered, and more testimonies are given.

All the information is presented in a friendly, conversational manner. Dunstan acknowledges that although her system is simple, it may not always be easy to discern the baby's words. Consequently, she offers helpful tips, including an assurance that baby's needs come first and that it is better to settle your baby as you normally would than to allow baby to become distressed while trying to identify the word. Parents are reminded that they can always try again later.

The material in Dunstan Baby Language conforms to the Lamaze Approach to Parenting. It encourages close, consistent interaction between parents and baby and recognizes that parenting is a learned skill. The videos' clear explanations and common-sense solutions make the Dunstan Baby Language set of DVDs an asset to an early parenting class as a way to foster confidence. My two caveats are that no fathers or partners are featured in the DVDs and that with less than 60 minutes of content, the information could easily be condensed to one DVD, making it more affordable.

Reviewer:

Jessica Koester, CD(DONA), LCCE

Parlin, NJ

\section{Hab It - Pelvic Floor}

Producer: PT Partners, LLC (2008)

Format: DVD (1 hour, 42 minutes); includes exercise band

Cost: $\$ 29.95$

Where to order: Online at www.hab-it.com

Hab It: Pelvic Floor is a DVD that provides an athome exercise regimen for women suffering the symptoms of incontinence, prolapse, or pelvic floor pain. By following the step-by-step instructions presented in Hab It: Pelvic Floor, the producers suggest that women can strengthen the levator ani muscle and the other muscles that make up the pelvic floor, leading to greater control over bodily function. This can be done in as short a time as 6 weeks by performing the recommended exercises 3 times a week. The DVD is designed to help women develop the confidence to perform their exercises independently.

The Hab It: Pelvic Floor DVD is broken into manageable sections of time. The introduction compassionately opens the topic in a respectful way. The host explains that because she suffered from incontinence after the birth of her children, she devoted her work as a physical therapist to this topic and to helping to relieve its symptoms. She motivates viewers as she explains that despite suffering from incontinence after the birth of her third child, she was able to return to her triathlon competitions within weeks of taking up the exercises presented in the DVD.

Two 6-minute segments on anatomy overview, Kegel instructions, and postural positioning are included. In the more detailed sections of the program, four workouts are presented, varying from 13-28 minutes in length. As viewers progress in their understanding of how to do the workouts, they can skip to shortened forms of the workouts, which vary from 8-23 minutes.

The main content of Hab It: Pelvic Floor is its workouts, which require participants to be able to sit, stand, and lie on their side, back, or belly. The workouts show subtle, small movements that isolate muscles in the lower back, abdomen, inner thighs, and pelvic floor. Despite varying levels of fitness, most women would be able to perform these simple exercises. 
Hab It: Pelvic Floor is ethnically diverse. It depicts women of many shapes and ages. It recommends using a Swiss ball and a soft ball, but a chair and a pillow may be substituted. An exercise band is included with the purchase of the DVD.

Although it is possible to choose some brief segments of Hab It: Pelvic Floor to use in childbirth education classes, mothers might benefit best by viewing the video at home. Hab It: Pelvic Floor is a much-needed DVD that will benefit many women.

Reviewer:

Connie Sultana, BA, CD(DONA), LCCE

Rohnert Park, CA

Interested in writing brief reviews of books or DVDs hot off the press? Have a new resource you think deserves to be reviewed? Contact Teri Shilling at her e-mail address (teri@ passionforbirth.com).
All reviews appearing in this column are intended solely for the use of our readers. The statements and opinions presented here are solely those of the individual reviewers, do not represent the opinions or official position of Lamaze International or The Journal of Perinatal Education, and do not constitute an endorsement of the reviewed material. The reviews cannot be used in advertising or for any other commercial purpose without written consent from Lamaze International. Lamaze International will take all available measures to prevent the unauthorized commercial use of its materials, its name, or the name of The Journal of Perinatal Education.

TERI SHILLING is the program director for Passion for Birth, a Lamaze-accredited childbirth education program. She is also the creator of The Idea Box for the Creative and Interactive

Childbirth Educator. 